\title{
Community health worker knowledge and management of pre-eclampsia in southern Mozambique
}

Helena Boene ${ }^{1}$, Marianne Vidler², Orvalho Augusto ${ }^{1,3}$, Mohsin Sidat $^{3}$, Eusébio Macete ${ }^{1,4}$, Clara Menéndez ${ }^{1,5}$, Diane Sawchuck ${ }^{6}$, Rahat Qureshi ${ }^{7}$, Peter von Dadelszen ${ }^{8}$, Khátia Munguambe $^{1,3}$, Esperança Sevene ${ }^{1,3^{*}}$ and the CLIP Feasibility Working Group

\begin{abstract}
Background: Mozambique has drastically improved an array of health indicators in recent years, including maternal mortality rates which decreased $63 \%$ from 1990-2013 but the rates still high. Pre-eclampsia and eclampsia constitute the third major cause of maternal death in the country. Women in rural areas, with limited access to health facilities are at greatest risk. This study aimed to assess the current state of knowledge and the regular practices regarding pre-eclampsia and eclampsia by community health workers in southern Mozambique.

Methods: This mixed methods study was conducted from 2013 to 2014, in Maputo and Gaza Provinces, southern Mozambique. Self-administered questionnaires, in-depth interviews and focus group discussions were conducted with CHWs, district medical officers, community health workers' supervisors, Gynaecologists-Obstetricians and matrons. Quantitative data were entered into a database written in REDCap and subsequently analyzed using Stata 13. Qualitative data was imported into NVivo10 for thematic analysis.

Results: Ninety-three percent of CHW had some awareness of pregnancy complications. Forty-one percent were able to describe the signs and symptoms of hypertension. In cases of eclampsia, CHWs reported to immediately refer the women. The vast majority of the CHWs surveyed reported that they could neither measure blood pressure nor proteinuria (90\%). Fewer reported confidence in providing oral antihypertensives (14\%) or injections in pregnancy (5\%). The other community health care providers are matrons. They do not formally offer health services, but assists pregnant women in case of an emergency. Regarding pre-eclampsia and eclampsia, matrons were unable to recognise these biomedical terms.

Conclusions: Although CHWs are aware of pregnancy complications, they hold limited knowledge specific to pre-eclampsia and eclampsia. There is a need to promote studies to evaluate the impact of enhancing their training to include additional content related to the identification and management of pre-eclampsia and eclampsia.

Keywords: Community health workers, Knowledge, Pre-eclampsia, Eclampsia management, Mozambique

Abbreviations: AMOG, Associação Moçambicana de Ginecologia; ANC, Antenatal care; AP, Administrative posts; APEs, Agentes Polivalentes Elementares; CHW, Community health worker; CISM, Manhiça health research center; CLIP, Community level interventions for pre-eclampsia; CRCT, Cluster randomized control trial; HDP, Hypertensive disorders of pregnancy; LMIC, Low and middle-income countries; TBAs, Traditional birth attendants; UBC, University of British Columbia; WHO, World health organization
\end{abstract}

\footnotetext{
* Correspondence: Esevene68@gmail.com

${ }^{1}$ Centro de Investigação em Saúde da Manhiça (CISM), Rua 12, Vila da

Manhiça CP 1929, Moçambique

${ }^{3}$ Universidade Eduardo Mondlane, Faculdade de Medicina, Av. Salvador

Allende, 702 R/C, Maputo, Moçambique

Full list of author information is available at the end of the article
} 


\section{Plain English summary}

Maternal mortality is an important public health issue in Mozambique despite the fact that some of these deaths are related to avoidable conditions. Women in rural areas, with limited access to health facilities are the most affected. Hypertensive disorders of pregnancy (HDP) are the third major cause of maternal death in the country. This study aimed to assess the current state of knowledge and routine practices regarding HDP by community health workers (CHW). This mixed methods study was conducted from 2013 to 2014, in southern Mozambique involving CHWs, district medical officers, community health workers' supervisors, GynaecologistsObstetricians and matrons. Ninety-three percent of $\mathrm{CHW}$ had some awareness of pregnancy complications and forty-one percent were able to describe the signs and symptoms of hypertension. In case of severity, CHWs reported to immediately refer the women. The vast majority of the CHWs surveyed reported that they could neither measure blood pressure nor proteinuria (90\%). Fewer reported confidence in providing oral antihypertensives (14\%) or injections in pregnancy (5\%). Although CHWs are aware of pregnancy complications, they hold limited knowledge specific to HDP. There is a need to promote studies to evaluate the impact of enhancing their training to include additional content related to the identification and management of HDP.

\section{Background}

Mozambique has progressively improved an array of health indicators over the last two decades, including a $63 \%$ decrease in maternal mortality from 1,300 in 1990 to 480 deaths per 100,000 live births in 2013 [1]. However, women still have a 1 in 40 lifetime risk of maternal death [2] chiefly due to avoidable causes including postpartum hemorrhage, maternal sepsis and pre-eclampsia and eclampsia that still need to be addressed [3, 4]. The hypertensive disorders of pregnancy (HDP) contribute significantly to high rates of maternal and perinatal death. In Mozambique, eclampsia alone is the third most common obstetric cause of maternal death [5]. The shortage of health professionals capable of responding to the need to reduce maternal mortality is also a concern. In 2011, the total number of medical doctors in the $\mathrm{Na}$ tional Health System in Mozambique was 1,268 for a population of approximately 22.3 million people (5.6 medical doctors per 100,000 inhabitants) [6], putting Mozambique in position of one of the worse countries according to the World Health Organization (WHO) Work Force Observatory [7]. To overcome the shortage of medical doctors in the country, nurses and clinical officers have been trained to take some of their duties [8].

To best reach vulnerable population in light of the 1978 Alma Ata Declaration, calling for primary health care for all at a time of widespread health care worker shortages in low and middle-income countries (LMIC) [9], many countries with lack of human resources adopted polices to train non-physician clinicians mainly to support care of women and children [10]. A reflection of such policies was the development of community health worker (CHW) programmes to expand access to maternal and child care particularly in rural areas [11-13].

Mozambique introduced CHWs, known as Agentes Polivalentes Elementares (APE), in 1978. CHWs are selected from and serve the communities in which they live, with a high level community participation in their selection process. CHWs are expected to dedicate $80 \%$ of their time on activities related to health promotion and diseases prevention and $20 \%$ to provide basic curative care [14]. Some of their activities related to maternal care include promotion of antenatal care and postpartum visits, promotion of health facility based deliveries and exclusive breast feeding, identification of warning signs in pregnancy and referral to the health facility. Regarding child care apart of health promotion and some disease prevention knowledge, they are trained to manage malaria, diarrhoea and upper respiratory tract infections, identify warning signs in the new born and refer [14]. The initial CHW training lasts $14-18$ weeks and additional refresher courses are provided regularly [14]. Particularly to pre-eclampsia and eclampsia nothing was included in their training manual.

Pre-eclampsia is a particularly complex condition. Only recently non-physician clinicians within the health system are being trained to manage this disease. A study in Malawi demonstrated that different types of nonphysician clinicians are capable to care for pregnant women including identifying and providing preliminary care before referring to nearest health facility for further care [15]. In 2012, the WHO report on optimization of health workers' roles, recommended that a variety of health care providers within the health system level should be involved in the care of women with preeclampsia and eclampsia (namely nurses, midwives and associate clinicians) by providing antihypertensive and magnesium sulphate $\left(\mathrm{MgSO}_{4}\right)$ when appropriate [16]. Specifically for CHWs, there is lack of evidence regarding their potential role in the management of preeclampsia and eclampsia. Often CHWs are seen as option for care mainly in rural areas which leads to progressive increase in their scope of work and tasks. Recently, in Mozambique, for example, CHW were trained to also provide injectable contraception [17]. There are certain concerns regarding the ability of CHWs providing more differentiated health services, particularly due to their limited literacy and numeracy level and also because of their already relatively high 
workload. However, being present in rural communities with limited or no access to health care services, CHWs are regarded as most available option. Thus, within this scenario, we asked whether CHWs could be involved in the management of pre-eclampsia and eclampsia and thus contribute for further reduction in maternal mortality given that this condition is the third leading cause of maternal mortality.

The aim of this article is to present the current state of knowledge and practices among CHWs regarding pre-eclampsia and eclampsia in southern Mozambique. A better understanding of $\mathrm{CHWs}$ perspectives regarding pre-eclampsia and eclampsia management could also be useful for policy makers to design effective training strategies to improve maternal health care. Furthermore, the paper also aimed to identify gaps in current knowledge and guide future studies related to CHWs involvement in innovative packages of care such as to control and mitigate effects of pre-eclampsia and eclampsia in remote and rural communities.

For the purpose of this manuscript, CHWs are represented by formal community agents locally named "Agentes Polivalentes Elementares - APEs". Further, because at community level, pregnant women are also frequently cared by matrons, who are elder women in the community experienced in traditional methods of care whose skills are acquired on the basis of experience and usually taught by older and more experienced matrons $[18,19]$, they were also a subject-matter of this study.

\section{Methods}

\section{Study area}

This is a component of multi-country national cluster randomized control trial (cRCT) implemented in Nigeria, Mozambique, Pakistan and India, the CLIP (Community Level Interventions for Pre-eclampsia) study (NCT01911494). In Mozambique the cRCT is implemented in two provinces, namely Gaza and Maputo, in the southern part of the country (Fig. 1). This study aims to evaluate a community based intervention consisting in measure of blood pressure and proteinuria, clinical management of severe pre-eclampsia with metildopa and magnesium sulphate, ability to timely refer women to the nearest health facility and thus contribute for the reduction of maternal morbidity and mortality due to pre-eclampsia and eclampsia.

Southern Mozambique is geographically diverse, with coastal regions as well as large areas of landlocked agricultural land. Maputo Province includes the capital city, Matola, located $10 \mathrm{Km}$ west of Maputo city, the country's capital. Maputo province has a population of 1.098 million. Gaza Province has a total population of 1.362 million [20]. In general, provinces are divided into districts, administrative posts (AP), localities and neighbourhoods.
Each AP covers roughly 500-2,000 inhabitants. The APs included in this study area (Calanga, Maluana, Ilha Josina Machel, Três de Fevereiro, Magude, Messano, Macia, Xilembene, Chissano, Mazivila, Chongoene, Chicumbane and Chibuto) are largely impoverished rural areas where the predominant occupations are agriculture, livestock rearing, informal trading, migrant labour (mainly to South Africa), handicrafts, and work in private sugar and rice processing farms. Residents of these APs are mostly of the Changana ethnic group and speak a local dialect of the same name (for more details see Table 1).

\section{Study design}

This study is based on a formative research exercise conducted in preparation to the CLIP trial. The formative research comprised a mixed methods design, a detailed description of these methods is presented elsewhere [21].

Data collections was conducted based on forms and guides, which were developed centrally by the study coordination team, used in the other countries where the study had been previously conducted (Nigeria, India and Pakistan), and adapted to the local context of Mozambique.

Quantitative data were collected through selfadministered questionnaires completed by CHWs. The qualitative data were obtained through focus group discussions with matrons, and in-depth interviews with CHWs supervisors, district chief medical officers and Gynaecologists-Obstetricians. While CHWs, CHW supervisors, and district medical officers from all study area were eligible to participate, matrons were drawn from selected AP, namely Ilha Josina Machel-Calanga, Três de Fevereiro, Messano and Chongoene.

Data collection was complemented by a desk review of existing documents regarding involvement of CHWs in maternal and child health such as policies, guidelines, reports and manuals.

Self-administered questionnaires targeted all active CHWs within the study. Recruitment was done through contacts with the health facility to which they are linked. Data collection was conducted either in the health facility where each $\mathrm{CHW}$ reports or at the house of the CHW.

Focus groups were conducted with matrons. This group was selected because it is also considered as community based alternative point of care for pregnant women and it was important to explore their views and practices regarding pregnancy complications (including high blood pressure and convulsions), pregnancy management (antenatal care and treatment provision) to gain an understanding of the role of matrons in the context of expansion of the maternal health care at community 


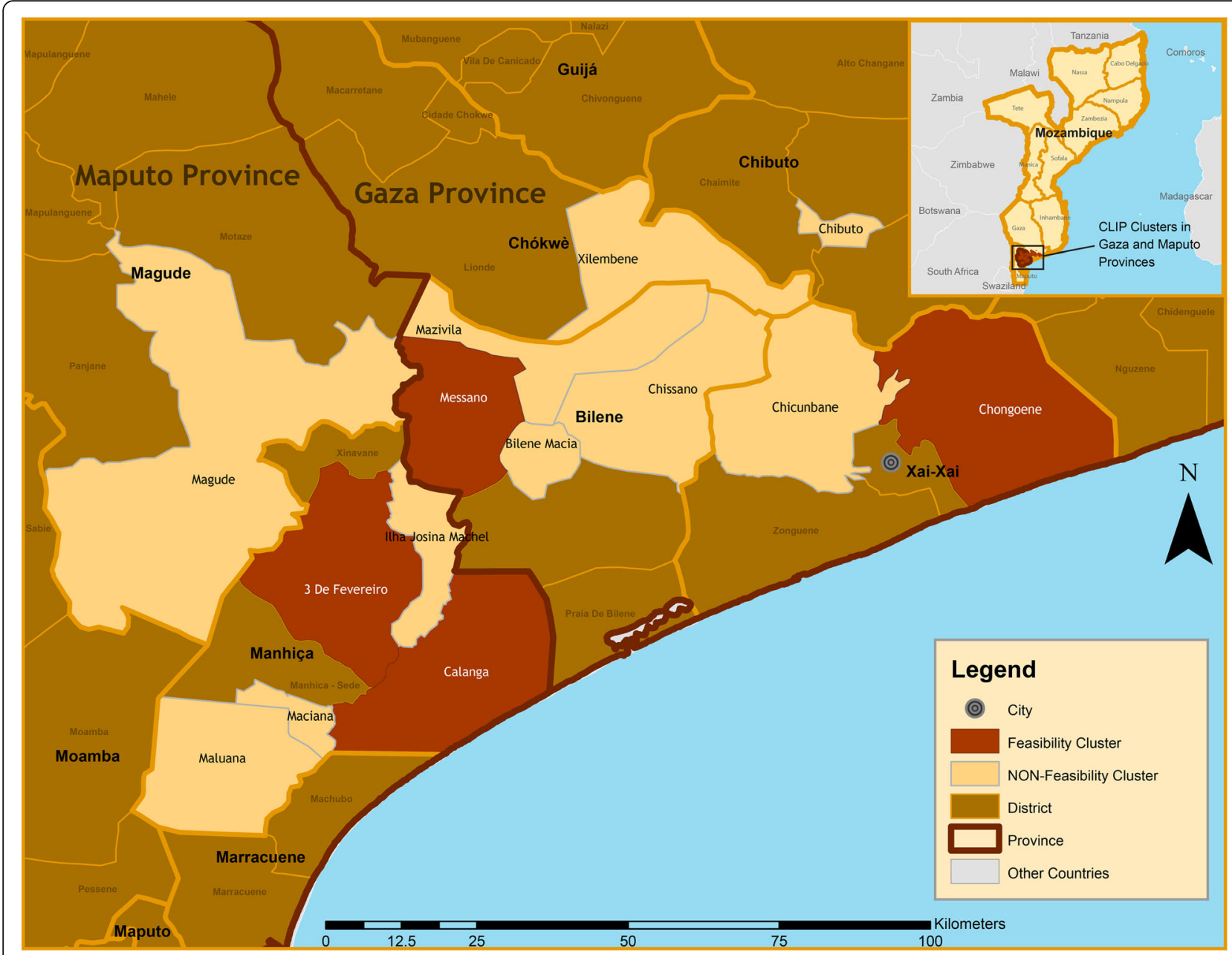

Fig. 1 Map of the study area

Table 1 Study site characteristics

\begin{tabular}{|c|c|c|c|c|c|c|c|}
\hline Province & Regions & Population & $\begin{array}{l}\text { Population of women } \\
\text { of reproductive age }\end{array}$ & $\begin{array}{l}\text { Number of } \\
\text { localities }\end{array}$ & $\begin{array}{l}\text { Number of } \\
\text { health facilities }\end{array}$ & $\begin{array}{l}\text { Number of } \\
\text { existing CHWs }\end{array}$ & $\begin{array}{l}\text { Number of CHWs } \\
\text { interviewed }\end{array}$ \\
\hline \multirow[t]{4}{*}{ Maputo } & Maluana-Maciane & 13,599 & 2,481 & 3 & 2 & 4 & 4 \\
\hline & Ilha Josina Machel-Calanga & 5,720 & 935 & 4 & 2 & 8 & 8 \\
\hline & Três de Fevereiro & 25,359 & 4,089 & 3 & 4 & 3 & 3 \\
\hline & Magude & 27,388 & 3,662 & 7 & 7 & 27 & 23 \\
\hline \multirow[t]{8}{*}{ Gaza } & Messano & 9,862 & 1,671 & 3 & 2 & 3 & 3 \\
\hline & Macia & 22,349 & 3,248 & 2 & 1 & 4 & 4 \\
\hline & Xilembene & 19,501 & 2,933 & 1 & 1 & 5 & 5 \\
\hline & Chissano & 18,286 & 2,950 & 3 & 3 & 3 & 3 \\
\hline & Mazivila & 14,875 & 2,215 & 3 & 2 & 4 & 4 \\
\hline & Chicumbane & 15,684 & 2,385 & 1 & 3 & 9 & 9 \\
\hline & Chibuto & 192,927 & 55,382 & 19 & 15 & 17 & 9 \\
\hline & Chongoene & 19,501 & 2,933 & 6 & 6 & 6 & 6 \\
\hline Total & 12 & 385,051 & 84,884 & 55 & 48 & 93 & 81 \\
\hline
\end{tabular}

Source: Unpublished data from demographic surveillance, health facility assessment (2014) and INE (2007) 
level. As matrons are not formally linked to the health facility and are not formally organized as a group therefore there is no clear ways to systematically identify and track them, their total number in the study area is unknown. After being identified with the assistance of neighbourhood chiefs they were invited to participate in the study. Focus groups were conducted either at the circulos (the usual community gathering location), or at the community leaders' house, as groups could easily be convened in these locations.

In-depth interviews, which involved all CHW supervisors and district medical officers from the study area were conducted one-on one in the work place of the respondents. The entry points were the district level medical officers themselves who in turn identified the CHWs supervisors. As there are no GynaecologistsObstetricians in none of the selected districts, they were identified through the Associação Moçambicana de Ginecologia (AMOG) - The Mozambican Gynaecologists and Obstetricians Association.

\section{Study procedures Desk review}

It was conducted to obtain information about existing CHWs and their distribution among study sites, their training profile and scope of work. A variety of documents were reviewed, and both published and unpublished information accounted for this exercise. Most of the published documents were downloaded from the Mozambique Government portal. These included formal policy documents and other official documents such as community involvement strategies, CHW training programmes, monitoring and evaluation manuals, and meetings' minutes and reports.

\section{Data collection}

Data were collected between October 2013 and May 2014. Questionnaires were designed to obtain information concerning $\mathrm{CHW}$ preparedness, knowledge and reported skills to manage pregnant women and to perform home-based basic treatment for women with pre-eclampsia. For the purpose of this study we assessed the following warning signs: high blood pressure, hemorrhage and convulsions. The questionnaire included 33 items on a five-point Likert scale. This format was regarded as appropriate to assess CHWs knowledge, attitudes and practices of $\mathrm{CHW}$ and level of confidence regarding maternal health care provision, and compare findings not only among all CHW' within the study area, but also eventually across the countries involved in the study. In addition, one open-ended question for respondents' comments or additional information was included. Depending on the number of CHWs per community, individual or collective briefing sessions were held to provide instructions on how to fill it, and when required further clarification was given in Changana. Five trained local social science research assistants were available for clarification when required. The questionnaire took on average $20 \mathrm{~min}$ to be completed by participants.

Focus groups discussion were used to explore the views of matrons regarding pregnancy complications (including high blood pressure and convulsions), pregnancy management (antenatal care and treatment seeking), and existing health care delivery practices. Based on the FGD guide, earlier mentioned the same trained local social science research assistants facilitated the discussions, which took on average $60 \mathrm{~min}$ and were audio recorded.

In-depth interviews were conducted with GynaecologistsObstetricians, district medical officers and CHW supervisors to allow further probing on pertinent issues, such as their opinions regarding CHW' ability to identify warning signs in pregnancy, manage pregnancy complications, and their proficiency to administer medications. These interviews were conducted by two social scientists. Interviews lasted between 30-60 min and were conducted in the workplace of participants. Field notes and audio recordings were taken at the time of in-depth interviews.

All data collection was led by a Mozambican social scientist assisted by 5 social science research assistants employed by CISM. These researchers were selected due to their familiarity with the local socio-cultural context, the research topic and their relevant qualitative and quantitative data collection expertise. Team members were fluent in Portuguese and Changana, included both male and female, and had no prior relationship with the participants. The data collection and analyse strategy was overseen by the study PI and co-PI.

\section{Data management and analysis}

Information obtained through the desk review was systematized and summarized to extract relevant information regarding CHWs history, role and challenges with regards to maternal and child health care that was already part of the scope of work of CHWs.

All data captured through questionnaires were sent to the Manhiça Health Research Center (CISM) for data entry and management using REDCap [22]. Double data entry was completed in all questionnaires. The presence of social science research assistants during the selfadministration of the CHWs questionnaires helped to maximise the data integrity. Before it was sent to the data Center, the study team members made a revision of each questionnaire while in the field. The failures to validation rules and double data entry discrepancies were checked through queries that led to confrontation with the paper forms. Outliers and missing values were also checked. Data was then exported to Stata 13 (Stata 
Corp., College Station, Texas, USA) for further statistical analysis. The demographic characteristics of CHWs and the study variables of interest are presented using descriptive statistics (absolute and relative frequencies, ranges, averages and quartiles). The exact logistic regression based odds-ratio and its $95 \%$ confidence intervals were used to describe the association between the selfreported ability of the CHWs to recognise warning signs in pregnancy with their demographic characteristics (age, sex, education and years of experience). Given the sample size no multivariate analysis was attempted.

Focus group discussions and in-depth interviews were digitally recorded using Olympus AS-2400 $\mathrm{PC}^{\ominus}$ recorders. Together with the open-ended question from $\mathrm{CHWs}$ questionnaire they were transcribed verbatim by the same team members who conducted data collection. While in-depth interviews data and that from the openended question of the $\mathrm{CHW}$ self-administered questionnaire were collected and transcribed in Portuguese. The focus group discussions were held in Changana and translated to Portuguese while being transcribed. Quality control of transcripts was ensured by listening to audio recordings and comparing them against the transcripts to confirm accuracy.

The qualitative data were analysed using NVivo version 10.0 (QSR International Pty. Ltd. 2012). A thematic analysis approach was taken (see Fig. 2). The coding structure (based on free nodes, branched nodes, attributes and some pre-determined queries) was developed in advance based on the study objectives through a collaborative discussion between researchers at CISM and University of British Columbia (UBC). Themes were subsequently adjusted and new themes added as they emerged from the data. As analysis was to be performed by two teams (CISM and UBC), the coding structured was in English.

The two Mozambican social scientists coded all transcriptions in Portuguese, by reading the text in Portuguese and labeling the concepts using the codes which were written in English. Three IDI and two FGD transcriptions were translated from Portuguese to English and coded by a social scientist based at UBC for three purposes: first, to support the discussions on the development of the coding structure; second, for the UBC collaborator to be familiar with the raw data, so as to assist interpretation; and finally, for quality control of the coding.

To allow the two teams to work independently, the data was split into two Nvivo projects, but the same coding structure was used for both teams. Coding consensus meetings to discussing data analysis strategy and findings were held via Skype ${ }^{\mathrm{Tu}}$. Coding agreement

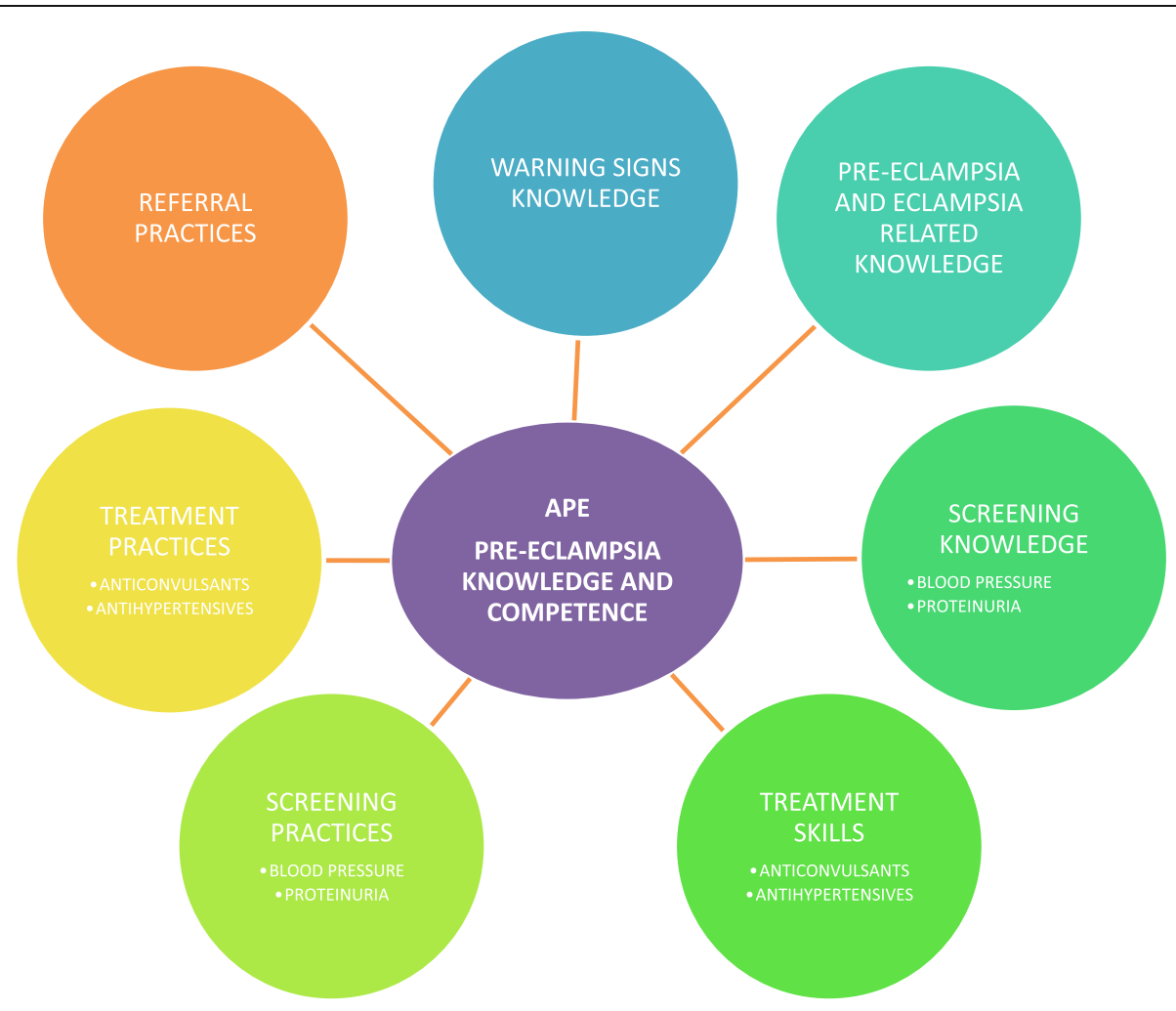

Fig. 2 Theme structure 
between the coders was very high. When the coding was completed the analysed data was merged into single project managed by the Mozambican team, form which the final queries were run.

\section{Ethical considerations}

Ethical approval for this study was granted by the CISM Institutional Review Board in Mozambique (CIBS_CISM/08/2013), as well as by the UBC C\&W Research Ethics Board in Canada (H12-00132). Written informed consent was sought from each participant before data collection. For the illiterate participants a literate witness was involved in the consent process whereby they were asked to read and explain to the participant the contents of the participant information sheet. The consent form was signed by the witness and the field worker, after the participant finger print was taken. All identifiable data of participants were codified through attribution of unique identification numbers or pseudonymous to guarantee anonymity. When needed the respondent was identified by stating the administrative post or the province in the illustrative quotes.

\section{Results}

\section{Participant characteristics}

In total, $81 \mathrm{CHW}$ were recruited to the study; corresponding to $87 \%$ of all CHW in the study area (see Tables 1 and 2). Four $\mathrm{CHW}$, all from Magude, were not included because they were not reachable at the time of recruitment to this study. Eight CHWs, all from Malehice, were not included because data collection took place around the flooding period when access to and communication with the health facilities, the recruitment entry points and data collection locations was not possible. All eighty-one questionnaire respondents were employed as $\mathrm{CHWs}$ at the time of data collection. Of those, $65 \%$ were female. For more details on participants' characteristics see Table 2.

Focus groups discussions were carried out with matrons from Ilha Josina Machel-Calanga, Três de Fevereiro, Messano and Chongoene, one for each AP. A total of five focus groups were conducted involving 46 participants in total, the median age was $43-67$ years and most of them did not have any formal education (Table 3). In total, eighty in-depth interviews were conducted: three CHW supervisors, three district medical officers, and two Gynaecologists-Obstetricians (Table 2).

\section{The role of community health workers in maternal care} $\mathrm{CHW}$ policy documents emphasise maternal and child health care. Although there is no indication on the number of visits per pregnant women policy documents state that CHWs should conduct regular home visits during pregnancy and postpartum (up to 42 days post-partum).
Table 2 Questionnaire and in-depth interview Participants' demographic information

\begin{tabular}{|c|c|c|}
\hline Characteristic & $\begin{array}{l}\text { CHWs (\%) } \\
N=81\end{array}$ & $\begin{array}{l}\text { Other health } \\
\text { professionals (\%) } \\
N=8\end{array}$ \\
\hline \multicolumn{3}{|l|}{ Age } \\
\hline $20-29$ & $14(17 \%)$ & $1(12 \%)$ \\
\hline $30-39$ & $12(15 \%)$ & $3(38 \%)$ \\
\hline $40-49$ & 25 (31 \%) & $3(38 \%)$ \\
\hline$>50$ & $21(26 \%)$ & $1(12 \%)$ \\
\hline Missing & $9(11 \%)$ & $0(0 \%)$ \\
\hline \multicolumn{3}{|l|}{ Gender } \\
\hline Male & $20(25 \%)$ & $3(38 \%)$ \\
\hline Female & $53(65 \%)$ & $5(62 \%)$ \\
\hline Missing & $8(10 \%)$ & $0(0 \%)$ \\
\hline \multicolumn{3}{|l|}{ Marital status } \\
\hline Married & $26(32 \%)$ & $3(38 \%)$ \\
\hline Divorced & $3(4 \%)$ & $0(0 \%)$ \\
\hline Widowed & $5(6 \%)$ & $0(0 \%)$ \\
\hline Single & $38(47 \%)$ & $5(62 \%)$ \\
\hline Missing & $9(11 \%)$ & \\
\hline \multicolumn{3}{|l|}{ Highest level of education attained } \\
\hline Primary level uncompleted & $39(48 \%)$ & $0(0 \%)$ \\
\hline Primary level completed & $15(19 \%)$ & $0(0 \%)$ \\
\hline Secondary level uncompleted & $14(17 \%)$ & $0(0 \%)$ \\
\hline Secondary level completed & $1(1 \%)$ & $4(50 \%)$ \\
\hline Higher degree & $0(0 \%)$ & $4(50 \%)$ \\
\hline Missing & $12(15 \%)$ & \\
\hline \multicolumn{3}{|l|}{ Years of experience has CHW } \\
\hline one year year & $21(26 \%)$ & NA \\
\hline Two years & 15 (19 \%) & NA \\
\hline Three years & $6(7 \%)$ & NA \\
\hline '3 years & 29 (36 \%) & NA \\
\hline Missing & 10 (12 \%) & NA \\
\hline
\end{tabular}

a 3 CHW supervisors (Bilene-Macia, Manhiça, Xai-Xai), 3 district medical officers (Bilene-Macia, Manhiça, Xai-Xai), 2 Gynaecologists-Obstetricians (Maputo city)

During these visits, $\mathrm{CHWs}$ interaction with pregnant women should focus mostly on health promotion, education and verification of antenatal care (ANC) attendance and to promote hospital-based delivery. The CHW training manual has a section dedicated to the care of pregnant women, with specific attention to pregnancy identification, the importance of early and regular ANC, and safe practices during pregnancy, birth preparedness counselling, the importance of delivering at the health facility and the identification of warning signs during pregnancy and delivery. Ninety-five percent of surveyed CHW reported that they are able to identify pregnant 
Table 3 Focus group participant's demographic information

\begin{tabular}{|c|c|c|c|c|c|c|c|}
\hline $\mathrm{Nr}$ & Group & Region & \# of Participants & Age (Median) & Marital status & Occupation & Schooling level \\
\hline 1 & Matrons & Calanga & 9 & 67 & $\begin{array}{l}\text { Married (3) } \\
\text { Widow (4) } \\
\text { Divorced (2) }\end{array}$ & Farmer (9) & Primary (9) \\
\hline 2 & & Ilha Josina Machel & 6 & 55 & $\begin{array}{l}\text { Married (3) } \\
\text { Widow (3) }\end{array}$ & Farmer (6) & $\begin{array}{l}\text { Never studied (5) } \\
\text { Primary (1) }\end{array}$ \\
\hline 3 & & Três de Fevereiro & 12 & 65 & $\begin{array}{l}\text { Married (4) } \\
\text { Widow (7) } \\
\text { Divorced (1) }\end{array}$ & Farmer (12) & $\begin{array}{l}\text { Never studied (9) } \\
\text { Primary (3) }\end{array}$ \\
\hline 4 & & Messano & 10 & 43 & $\begin{array}{l}\text { Married (5) } \\
\text { Widow (3) } \\
\text { Single (2) }\end{array}$ & $\begin{array}{l}\text { Farmer (8) } \\
\text { Teacher (1) } \\
\text { Housewife (1) }\end{array}$ & $\begin{array}{l}\text { Never studied (1) } \\
\text { Primary (7) } \\
\text { Secondary (2) }\end{array}$ \\
\hline 5 & & Chongoene & 9 & 58 & $\begin{array}{l}\text { Married (2) } \\
\text { Widow (1) } \\
\text { Single (6) }\end{array}$ & Housewife (9) & $\begin{array}{l}\text { Never studied (7) } \\
\text { Primary (2) }\end{array}$ \\
\hline
\end{tabular}

women in the community and $93 \%$ said that they monitor pregnant women on a regular basis (see Table 4).

According to focus group discussions, matrons reported to provide advice to women throughout pregnancy, particularly related to traditional practices. The matrons do not formally offer health services, but when there is an emergency in the community they might be called upon for assistance.

Supervisors and district medical officers, hold perceptions regarding the role of CHWs which are in accordance with the existing policy documents, as illustrated in the quote bellow.

"What they [CHWs] do when they find a pregnant woman is to refer the health facility for antenatal care, to raise awareness of the importance of antenatal consultation [and] giving birth at the health facility.

It is what they do, and they issue a referral slip [...] to health facility. They always make regular visits until [...] after childbirth also [they] have to make follow-up to see if the child up to five years for example has completed the vaccinations [programme]. They always have to make regular visits to that family".- CHWs supervisor, IDI, Gaza

\section{Community health worker knowledge of the warning signs in pregnancy}

CHWs training covers the identification of pregnancy warning signs, such as vaginal bleeding, fever, swelling, convulsions, severe headache, lower abdominal pain, absence of fetal movements, and weight loss.

More than half of the CHWs reported having received regular training regarding the identification of complications in pregnancy $(60 \%)$ and most $(93 \%)$ agreed that they knew the warning signs in pregnancy. Yet, less than half (38\%) of them reported not being able to identify warning signs during delivery (see Table 4). Concerning to age, older CHWs had slightly higher chance of knowing at least one warning sign in pregnancy $(\mathrm{OR}=$ 1.14; 95 \% CI: 1.02-1.34), with relative increase associated with each year of experience or practice. However, no statistically significant association was observed for gender and education level (see Table 5).

Regarding haemorrhage, $69 \%$ of CHWs who responded to the questionnaire, reported to be able to identify haemorrhage during pregnancy. Related to preeclampsia, only $41 \%$ of CHWs reported to know at least one warning sign of hypertension in pregnancy (see Table 4). Female CHWs were less likely (OR $=0.28$; $95 \%$ CI: $0.08-0.92)$ to have knowledge on the warning signs of hypertension in pregnancy compared to male CHWs. This difference was not observed when comparing age, education level and years of work as CHW (see Table 5).

Seventy percent of CHWs believed they could recognise the signs of convulsions. No significant differences were observed according to the demographic variables of interest. Regarding skills to detect pre-eclampsia and eclampsia, only $10 \%$ of CHWs reported having the capacity to measure blood pressure and proteinuria (see Table 4).

Despite not having formal training and their marginal role in the care of pregnant women in rural communities, matrons reported having knowledge of pregnancy, its complications and were able to identify warning signs such as unconsciousness, short of breath, weakness, fever, and headache. Regarding pre-eclampsia and eclampsia, matrons were unable to recognise these biomedical terms, but could list several symptoms related to these conditions including high blood pressure, convulsions and loss of consciousness. Matrons were unable to establish a direct association between specific warning signs and maternal death, except for fainting. In such cased, they perceived that the patient dies, not because the immediate physiological implications of convulsions or loss of conscience. 
Table 4 Community health workers' questionnaire results

\begin{tabular}{|c|c|c|c|c|}
\hline & Agree & $\begin{array}{l}\text { Neither Agree } \\
\text { nor Disagree }\end{array}$ & Disagree & Unknown \\
\hline Identify pregnant women & $77(95 \%)$ & $0(0 \%)$ & $3(4 \%)$ & $1(1 \%)$ \\
\hline Monitor regularly pregnant women & $75(93 \%)$ & $2(2 \%)$ & $2(2 \%)$ & $2(3 \%)$ \\
\hline Know the warning signs in pregnancy & $75(93 \%)$ & $0(0 \%)$ & $3(4 \%)$ & $3(3 \%)$ \\
\hline Know the warning signs of hypertension during pregnancy & $33(41 \%)$ & $0(0 \%)$ & $32(40 \%)$ & $16(19 \%)$ \\
\hline Know the warning signs of convulsions in pregnancy & $57(70 \%)$ & $2(3 \%)$ & $18(22 \%)$ & $4(5 \%)$ \\
\hline Can identify haemorrhage during pregnancy & $56(69 \%)$ & $0(0 \%)$ & $18(22 \%)$ & $7(9 \%)$ \\
\hline Can identify warning signs during labour & $33(41 \%)$ & $1(1 \%)$ & $31(38 \%)$ & $16(20 \%)$ \\
\hline Can measure blood pressure & $8(10 \%)$ & $0(0 \%)$ & $45(56 \%)$ & $28(34 \%)$ \\
\hline Can measure proteinuria & $8(10 \%)$ & $4(5 \%)$ & $42(52 \%)$ & $27(33 \%)$ \\
\hline Can provide oral medication & $38(47 \%)$ & $0(0 \%)$ & $25(31 \%)$ & $18(22 \%)$ \\
\hline Can provide oral antihypertensives & $11(14 \%)$ & $1(1 \%)$ & $39(48 \%)$ & $30(37 \%)$ \\
\hline Can give injections to pregnant women & $4(5 \%)$ & $2(2 \%)$ & $47(58 \%)$ & $28(35 \%)$ \\
\hline $\begin{array}{l}\text { I receive additional training regarding identification and referral of pregnant women with } \\
\text { complications }\end{array}$ & $50(62 \%)$ & $0(0 \%)$ & $24(30 \%)$ & $7(8 \%)$ \\
\hline I receive regular training to identify complications in pregnancy & $49(60 \%)$ & $0(0 \%)$ & 25 (31 \%) & 7 (9 \%) \\
\hline
\end{tabular}

\section{Community health worker management and referral practices for pregnancy complications}

Sixty-two percent of CHWs reported having received additional training regarding identification and referral of pregnant women with complications as part of regular continuous education programme. Nearly half of the CHWs reported being confident in providing oral medication of any kind ( $47 \%$ ), but a much lower proportion $(14 \%)$ reported confidence in specifically providing oral antihypertensives. Very few CHWs (5 \%) felt confident in administering injections of any kind (see Table 4).

CHWs supervisors, district medical officers and Gynaecologists-Obstetricians showed support for taskshifting to $\mathrm{CHWs}$ regarding the identification and timely referral of cases before progression to severe preeclampsia and eclampsia. However, they showed strong skepticism regarding $\mathrm{CHWs}$ ' ability to manage the cases at community-level.

Table 5 Self-reported ability of CHWs to recognise warning signs in pregnancy, pregnancy related HTA, and convulsions in pregnancy

\begin{tabular}{|c|c|c|c|c|c|c|c|}
\hline & \multirow{2}{*}{$\begin{array}{l}\text { Total } \\
\text { N (\%) }\end{array}$} & \multicolumn{2}{|c|}{$\begin{array}{l}\text { Recognise pregnancy warning } \\
\text { signs }{ }^{\mathrm{b}}\end{array}$} & \multicolumn{2}{|c|}{$\begin{array}{l}\text { Recognise pregnancy hypertension warning } \\
\text { signs }\end{array}$} & \multicolumn{2}{|c|}{ Recognise convulsions } \\
\hline & & $\overline{N(\%)}$ & OR $(95 \% C l)^{a}$ & $\overline{N(\%)}$ & OR $(95 \% \mathrm{Cl})^{\mathrm{a}}$ & $\overline{N(\%)}$ & OR $(95 \% C l)^{a}$ \\
\hline Total & $81(100.0)$ & 75 (92.6) & & $33(40.7)$ & & $57(70.4)$ & \\
\hline \multicolumn{8}{|l|}{ Sex } \\
\hline Male & $20(24.7)$ & $19(95.0)$ & 1.00 & $13(65.0)$ & 1.00 & $18(90.0)$ & 1.00 \\
\hline Female & $53(65.4)$ & $50(94.3)$ & $0.88(0.02-11.74)$ & $18(34.0)$ & $0.28(0.08-0.92)^{*}$ & $34(64.2)$ & $0.20(0.02-1.00)$ \\
\hline Missing & $8(9.9)$ & $6(75.0)$ & $0.17(0.00-3.82)$ & $2(25.0)$ & $0.19(0.02-1.44)$ & $5(62.5)$ & $0.20(0.01-2.24)$ \\
\hline \multicolumn{8}{|l|}{ Age } \\
\hline Median (IQR) & $46.0(35.5-50.0)$ & - & $1.14(1.02-1.34)^{*}$ & - & $0.99(0.95-1.03)$ & - & $0.99(0.95-1.03)$ \\
\hline \multicolumn{8}{|l|}{ Education } \\
\hline Primary & $54(66.7)$ & $52(96.3)$ & 1.00 & $22(40.7)$ & 1.00 & $38(70.4)$ & 1.00 \\
\hline Secondary & $15(18.5)$ & 14 (93.3) & $0.54(0.03-34.01)$ & $7(46.7)$ & $1.27(0.34-4.68)$ & $11(73.3)$ & $1.16(0.28-5.73)$ \\
\hline Missing & $12(14.8)$ & $9(75.0)$ & $0.12(0.01-1.21)$ & $4(33.3)$ & $0.73(0.14-3.15)$ & $8(66.7)$ & $0.84(0.19-4.39)$ \\
\hline \multicolumn{8}{|c|}{ Years working as community health worker } \\
\hline Median (IQR) & $2(1-8)$ & - & $1.19(0.93-1.94)$ & - & $1.04(0.97-1.12)$ & - & $1.09(0.99-1.24)$ \\
\hline
\end{tabular}

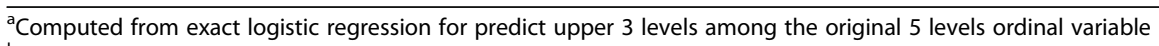

${ }^{b}$ Recognised at least one warning sign

*Overall $p$-value $<0.05$ 
"I think that it would not be ideal...blood pressure is not just any pathology which we can say: let's create an algorithm and give it to them [CHWs] because blood pressure acts in different ways in each patient, thus it is a pathology that has to be managed by experienced people...people who are trained for that. However, if well trained they can measure blood pressure only if based on electronic devises, and refer the women to the nearest health facility".- Chief medical officer, IDI, Maputo

The scepticism was even stronger, when discussing the consideration of administration of injectable medication by CHWs to manage severe pre-eclampsia and eclampsia.

\section{Even if they are well trained [to administrate magnesium sulphate in the community], I would not support... I think that this will perhaps increase maternal deaths related to hypertensive disorders in the community... will he [CHWs] have and know how to correctly use magnesium sulphate in order to control hypotension and respiratory depression, for example?".- Gynaecologists-Obstetricians, IDI, Maputo}

This lack of support was based on their perceptions regarding CHWs limited clinical knowledge and their eventually inability to manage adverse events of injectable drugs. They also showed concerned about CHWs limited literacy and numeracy levels and short duration of their initial training which does not include administration of injectable drugs. They insisted that in cases of an emergency, including convulsions, CHWs should immediately refer to the nearest health facility using the referral slip with the following information: date, name of the patient, age, community, referral facility, CHWs' name, reported symptoms and signs, and any first aid or care provided.

Historically, matrons managed women during pregnancy and delivery. According to focus group findings, matrons reported to currently have less of a role in maternal care, since according to them, the Ministry of Health advised them not to manage emergencies and deliveries at home and encouraged women to seek antenatal care and delivery at health facilities.

"Yes we help [women] giving birth but with the arrival of the hospital we were forbidden [by the Ministry of Health]. [Women] should go to the hospital. It is not because we cannot do [the] birth. We cannot do, our time ended up. And now we cannot get involved in these new things [new rules]. Our daughters are brought to hospital now". Matrons, FGDs, Calanga
However, matrons reported to still assist with deliveries outside facilities, particularly when they have a request in the late stages of labour. In the management of pregnancy complications, matrons typically use traditional methods. For example, in cases of abortion, matrons boil herbs in water, put them in a clay pot and seal it until the day of delivery. Similarly, when matrons encounter women with convulsions they treat them based on their traditional knowledge (exposing them to strong smells) before referring to a health facility.

\section{Discussion}

This study was conducted to better understand the potential of CHWs, particularly in the provision of obstetric care at community level, with focus on pre-eclampsia and eclampsia. There were no previously published studies regarding the knowledge or competency of CHWs in identifying or managing HDPs in Mozambique. This analysis showed that despite the fact that CHWs had no specific training for identification, management and referral of pregnant women with pre-eclampsia and eclampsia, a considerable number of them reported that can identify some warning signs commonly occurring in pregnancy including: convulsions, headache, swelling among other signs. The finding that most CHWs agreed that they knew the warning signs in pregnancy likely results from the training that they receive on this topic in preparation to becoming CHWs. The ability of CHWs to identify warning signs in pregnancy is somewhat encouraging, not enough especially with regards to the link between the warning signs and the respective conditions, considering that identification of pregnant women with complications is included in their responsibilities. There is further need to improve their knowledge about pre-eclampsia and eclampsia, particularly raising their awareness on the link between hypertension and convulsions during pregnancy and on need of urgent referring pregnant women with pre-eclampsia and eclampsia being both life-threatening conditions.

Few studies assessed CHW knowledge and competencies specifically related to HDP. One study in Ghana, however, showed that CHWs reported a range of blood pressure thresholds in pregnancy, and these providers did not uniformly mention that hypertension in pregnancy was warning sign that needing referral [23]. Another study, in South Africa reviewed CHW knowledge, beliefs and attitudes related to hypertension in the general population, and found that CHWs were unaware of the causes, outcomes, prevention, and management of it. Moreover, they tended to believe in the use of traditional treatments for hypertension instead of evidence-based biomedical care, leading researchers to ultimately conclude that these health workers had insufficient biomedical knowledge related to hypertension [24]. 
Gender and age were the demographic characteristics which showed association with knowledge. The impact of age on this outcomes may be related to life cumulative experience as alone the years of practices as $\mathrm{CHW}$ did not shown any differences. It was surprising that male CHWs showed more knowledge in relation to warning signs of hypertension when compared to female CHWs. This is an important topic for further discussions and should be addressed while scaling up the intervention taking into account that gender issues can pose barriers to implementation of maternal care [25]. This study did not find significant differences in CHW knowledge according to the level of education or years of work as CHW. Despite this result, supervisors believe that CHWs' education level was insufficient for the provision of treatment for pre-eclampsia or eclampsia. The ability to identify warning signs demonstrates that the training content is adequately recalled by CHWs, suggesting that when are well trained they can acquire practical knowledge and implement community-based interventions that can contribute to reduce maternal mortality.

Moreover, CHWs currently have health promotion and management responsibilities for other diseases such as malaria, diarrhoea and upper respiratory tract infections. The implementation of these activities has been successfully reported in various settings, suggesting that despite their low level of literacy and numeracy, with appropriate training and supervision they are capable of providing more differentiated health services at the community-level [26].

It was evident from questionnaire responses, that CHWs are not currently equipped to identify and manage hypertension in pregnancy. This is in accordance with the absence of these topics in their training manuals. Further studies to evaluate the impact of providing equipment and adequate training to assess blood pressure, measure proteinuria and manage pre-eclampsia and eclampsia should be promoted in Mozambique. It has been demonstrated in Nepal that with appropriate training of maternal health interventions, knowledge, competencies and skills can be substantially improved among village midwives [27].

This study has shown that CHWs were under pressure to refer pregnant women with pregnancy complications to the health facilities as recommended during their training, but their inability to identify most of the warning signs specific for pre-eclampsia and eclampsia may delay these referrals. A study of risk factors for eclampsia in Mozambique revealed that most referral cases reported no blood pressure measurements in antenatal clinics, indicating poor identification of women at risk [28].

CHWs seem to accept to expand their role to include management of pre-eclampsia and eclampsia although few showed confidence in administering injectable medication which is essential for the management of severe cases. This low self-confidence is also reflected among supervisors, medical officers, including specialists who believe that the CHWs are not prepared to identify and manage any complications raised from the administration of magnesium sulphate or other injectable drugs. This general scepticism can also be attributed to the fact that CHW training does not currently include administration of injectable drugs. This should be properly addressed for the successful expansion of programmes based on community interventions in the Mozambican context, also taking into account factors such as burden of work due to additional interventions, duration and quality of CHWs training, regular supervision and medication stock management [29]. Misconceptions amongst some in the medical community regarding the potential dangers of magnesium sulphate has contributed to the drug's non-use [30]. Such misunderstandings may also lead to suboptimal practice, such as infrequent blood pressure and proteinuria measurement, and the use of diazepam in place of magnesium sulphate [31, 32]. At PHC level midwives are trained to, and therefore should be able to, identify and treat women with pre-eclampsia [33]. However, in Afghanistan, midwives did not identify the need for continued antihypertensive therapy in $34 \%$ of cases [32]. Midwives, nurses and medical doctors alike have demonstrated poor performance on knowledgebased exams regarding pregnancy complications in Benin, Ecuador, Jamaica and Rwanda, the scores ranged from $51 \%$ to $78 \%$ on HDP-related questions [34]. Nurses and Auxiliary Nurse Midwives in Nepal similarly showed poor knowledge and skills, related to diagnosis, management and monitoring of severe pre-eclampsia and eclampsia [27]. Nevertheless, a study in Afghanistan has shown encouraging findings, the midwives where highly confident in the administration of magnesium sulphate $(79 \%$ were very confident, while $16 \%$ had some reservations) [32].

Regarding evidence of the implementation of community based management of pregnant women, a study in Uganda suggests that trained $\mathrm{CHW}$ can safely provide injectable contraceptives [35]. A literature review by Malarcher (2010) also found consistent evidence that CHWs could provide injections safely, were comfortable with their ability to administer injections, and their clients were satisfied [36]. A study in Madagascar confirmed that clients were satisfied with services received from the CHW (including their administration of contraceptive injections) [37]. Many other countries have illustrated the importance of the work provided by CHWs and how they are highly regarded in their communities [33]. It is therefore reassuring that this is a window of opportunity to include tasks that are critical for 
maternal survival, such as administration of antihypertensive drugs. There is a need of further research addressing the ability to administer injectables by $\mathrm{CHW}$ in Mozambique.

Besides CHW, matrons are important and well recognised cadres of community-based maternal health care providers. However, the results of this study have shown that they are discouraged to assist emergencies and deliveries at home. Similar results were found in Ghana, where the traditional birth attendants (TBAs) were discouraged to undertake deliveries but to refer cases to health centres [38]. The role of matrons in pregnancy management may be reconsidered due to the shortage of health professionals in remote areas. The accuracy and effectiveness of matrons' knowledge and competence is not well known, as most matrons do not receive formal training. Their skills are acquired on the basis of experience and usually taught by older and more experienced matrons $[18,19]$. Training, supervision and provision of basic equipment and better coordination between matrons and health facilities would add value to their contribution in pregnancy care. It is increasingly recognized that TBAs or matrons may have a role to play in improving health outcomes in developing countries because of their access to communities and the relationship they share with women in local communities especially if women are unable to access skilled care due to long distance from health facilities, lack of money, lack of available transportation and poor health facility conditions $[38,39]$.

Efforts to include specific maternal health care interventions within the $\mathrm{CHW}$ package of training could contribute to a reduction in maternal morbidity and mortality.

\section{Strengths and limitations}

CHWs have limited literacy and numeracy, therefore, it is possible that some respondents faced difficulties in understanding elements of the questionnaire. To minimize this concern, researchers were present during completion of the questionnaires, which may also have placed pressure on respondents and eventually effected their responses. The team made clear that their role was only to clarify the questions and not to interfere with, nor judge the answers. It was not possible to collect data from eight CHWs in Chibuto due to flooding's; therefore, this group is not represented. No focus groups or interviews were conducted with $\mathrm{CHW}$ to complement surveys responses. The assessment of knowledge and self-efficacy through use of likert scales is limited. This method does not allow respondents to provide context to their responses. In spite of this limitation, closedended questions were felt to be most appropriate given the sample size required to obtain representative and cross-country findings and budgetary constraints to conduct in-depth data collection among such numbers of CHWs. Despite these limitations, this study has many strengths. Quantitative methods obtain from a large sample size allowed a good overall representation of the region. All data was collected and analysed by local researchers with familiarity of the region and sociocultural context. The mixed methods approach was an additional strength, as triangulation with the qualitative components enriched the quantitative results. This study provides novel findings regarding the knowledge and confidence in addressing the most pervasive pregnancy complications affecting Mozambicans today. Little literature is currently available regarding community health worker knowledge related to pre-eclampsia and eclampsia, and therefore these results provide unique insights.

\section{Conclusions}

The results of this study illustrates that CHWs are aware of pregnancy complications, but have limited knowledge with regards to pre-eclampsia and eclampsia. There is a need to promote studies to evaluate the impact of enhancing their training to include additional content related to the identification and management of preeclampsia and eclampsia. As community health workers and matrons are the first point of contact for primary care, particularly in remote rural areas where other health services are non-existent or difficult to access, appropriate training would enforce their ability to identify, stabilize, and refer obstetric emergencies.

\section{Additional file}

Additional file 1: Reviewer reports. (PDF $250 \mathrm{~kb}$ )

\section{Acknowledgements}

The authors would like to thank all participants in the study. They also gratefully acknowledge the contributions of the Community Level Interventions for Pre-eclampsia (CLIP) Feasibility Working Group: Rosa Pires, Zefanias Nhamirre, Rogério Chiaú, Analisa Matavele, Adérito Tembe, Lina Machai, Beth Payne, Sharla Drebit, Chirag Kariya and Laura Magee. We also acknowledge the support of CISM, University of British Columbia (UBC), Maputo Provincial Health Department (DPS Maputo), Gaza Provincial Health Department (DPS Gaza), Mozambican Obstetrics and Gynecology Association (AMOG), Faculty of Medicine of the Eduardo Mondlane University, Ministry of Health (MISAU), National Direction for Public Health, and Community Health Workers Programme. This work is part of the University of British Columbia PRE-EMPT (Pre-eclampsia/Eclampsia, Monitoring, Prevention and Treatment) initiative supported by the Bill \& Melinda Gates Foundation. CISM is funded by Agencia Española de Cooperación Internacional para el Desarrollo.

\section{Declarations}

This article has been published as part of Reproductive Health Volume 13 Supplement 2, 2016: Building community-level resilience for the case of women with pre-eclampsia. The full contents of the supplement are available online at http://reproductive-health-journal.biomedcentral.com/articles/supplements/volume-13-supplement-2. Publication charges for this supplement were funded by the University of British Columbia PRE-EMPT (Pre-eclampsia/ Eclampsia, Monitoring, Prevention and Treatment) initiative supported by the Bill \& Melinda Gates Foundation. 


\section{Authors' contributions}

HB drafted the manuscript and led data collection and analysis. ES adapted data tools, supported the analysis and interpretations of the quantitative data, provided oversight throughout project implementation and manuscript writing. KM adapted the tools to the local context, supervised HB, contributed to collection, analysis, interpretation of the qualitative data and revised the manuscript. MV provided critical manuscript revision, analyse qualitative data and provided insight for interpretation. DS and RQ contributed to the conception and design of the study. OA, MS, EM, CM and PvD provided intellectual input to manuscript development regarding the country and global context. All authors read and approved the final manuscript.

\section{Competing interests}

The authors declare that they have no competing interest.

\section{Peer review}

Reviewer reports for this article are included in Additional file 1.

\section{Author details}

'Centro de Investigação em Saúde da Manhiça (CISM), Rua 12, Vila da Manhiça CP 1929, Moçambique. ${ }^{2}$ Department of Obstetrics and Gynaecology, and the Child and Family Research Institute, University of British Columbia, 950 West 28th Avenue, Vancouver V5Z4H4, Canada. ${ }^{3}$ Universidade Eduardo Mondlane, Faculdade de Medicina, Av. Salvador Allende, 702 R/C, Maputo, Moçambique. ${ }^{4}$ Ministério da Saúde, Av. Eduardo Mondlane, Maputo 1008, Moçambique. ${ }^{5}$ Barcelona Institute for Global Health (ISGlobal) /Hospital Clinic - Universitat de Barcelona, Calle Rosselló, 132, Barcelona 08036, Spain. ${ }^{6}$ Department of Research, Vancouver Island Health Authority, Victoria V8R 1J8, Canada. ${ }^{7}$ Division of Women and Child Health, Aga Khan University, Karachi, Pakistan. ${ }^{8}$ Department of Obstetrics and Gynaecology, St George's University London, London SW17 ORE, UK.

\section{Published: 30 September 2016}

\section{References}

1. World Health Statistics 2014. Geneva; 2014. Availabe on: http:/apps.who.int/iris/ bitstream/10665/112738/1/9789240692671_eng.pdf?ua=1. Accessed 23 Aug 2016.

2. WHO, UNICEF, UNFPA WBG, Division and the UNP. Trends in maternal mortality 1990 to 2015. 2015; Available from: http://apps.who.int/iris/ bitstream/10665/194254/1/9789241565141_eng.pdf?ua=1 in Maternal Mortality 1990 to 2015 full report. PDF. Accessed 3 May 2016.

3. Granja AC, Machungo F, Bergstrom S. Avoidability of maternal death in Mozambique: audit and retrospective risk assessment in 106 consecutive cases. Afr J Heal Sci. 2000;7(3-4):83-7.

4. David E, Machungo F, Zanconato G, Cavaliere E, Fiosse S, Sululu C, et al. Maternal near miss and maternal deaths in Mozambique: a cross-sectional, region-wide study of 635 consecutive cases assisted in health facilities of Maputo province. BMC Pregnancy Childbirth [Internet]. 2014;14:401.

5. Menendez C, Romagosa C, Ismail MR, Carrilho C, Saute F, Osman N, et al. An autopsy study of maternal mortality in Mozambique: The contribution of infectious diseases. PLoS Med. 2008:5(2):0220-6.

6. WHO. Mozambique Health Workforce. Situational analysis. Regional Officer for Africa. Available on: http://www.afro.who.int/en/mozambique/country-programmes/ health-systems/human-resources-for-health.html. Accessed 24 Aug 2016.

7. WHO. World Health Organization Work Force Observatory [Internet]. [cited 2016 May 13]. Available from: http://gamapserver.who.int/gho/interactive_ charts/health_workforce/PhysiciansDensity_total/tablet/atlas.html. Accessed 23 Aug 2016.

8. Cumbi A, Pereira C, Malalane R, Vaz F, McCord C, Bacci A, et al. Major surgery delegations to mid-level health practitioners in Mozambique: health professional's perceptions. Hum Resour Health. 2007;5:27.

9. Declaration of Alma Ata. In: International Conference on primary Health care. Alma-Ata; 1978

10. Fulton BD, Scheffler RM, Sparkes SP, Auh EY, Vujicic M, Soucat A. Health workforce skill mix and task shifting in low income countries: a review of recent evidence. Hum Resour Health. 2011;9:1.

11. Saprii L, Richards E, Kokho P, Theobald S. Community health workers in rural India: analysing the opportunities and challenges Accredited Social Health Activists (ASHAs) face in realising their multiple roles. Hum Resour Health. 2015;13(1):95.
12. Okuga M, Kemigisa M, Namutamba S, Namazzi G, Waiswa P. Engaging community health workers in maternal and newborn care in eastern Uganda. Glob Health Action. 2015;8(1):1-10.

13. Lassi ZS, Das JK, Salam RA, Bhutta ZA. Evidence from community level inputs to improve quality of care for maternal and newborn health: intervention and findings. Reprod Health. 2014;11 suppl 2:S2.

14. Chilundo BG, Cliff JL, Mariano AR, Rodriguez DC, George A. Relaunch of the official community health workers programme in Mozambique: is there a sustainable basis for iCCM policy? Health Policy Plan. 2015;30(2):ii54-64.

15. Ellard DR, Chimwaza W, Davies D, O'Hare JP, Kamwendo F, Quenby S, et al. Can training in advanced clinical skills in obstetrics, neonatal care and leadership, of non-physicians clinicians in Malawi impact on clinical services improvements (the ETATMBA project): a process evaluation. BMJ Open. 2014;4(8), e005551.

16. WHO. WHO Recomendations. Optumizing health worker role to improve access to key maternal and newborn health onterventions through task shifting. Geneva: OPTIMIZE MNH. 2012.

17. MISAU. Manual de Formacao dos Agentes Polivalentes Elementares (APES): Modulo II PROMOCAO DE SAUDE E PREVENCAO DE DOENCAS. Maputo; 2015. (2a Edicao Revisao).

18. Rodriques Z. Práticas culturais e comunitárias de promoção de saúde sexual e reprodutiva em 3 províncias de Moçambique: Nampula. Maputo: Sofala e Inhambane; 2010.

19. Gloyd S, Floriano F, Seunda M, Chadreque MA, Nyangezi JM, Platas A. Impact of traditional birth attendant training in Mozambique: A controlled study. J Midwifery Women's Heal. 2001;46(4):210-6.

20. INE. III Recenseamento Geral da Populacao e Habitacao. Maputo: Instituto Nacional de Estatistica. 2007; Available from: Cited 2016 April 26. Available from:http://www.ine.gov.mz/operacoes-estatisticas/censos/censo-2007/rgph2007/indicadores-socio-demograficos-provincia-de-maputo-2007.pdf/

21. INE. III Recenseamento Geral da Populacao e Habitacao. Gaza: Instituto Nacional de Estatistica. Reprod Health BMC. 2016;13(Suppl 1);56:1-15. Available from: Cited 2016 April 26. Available from: http://www.ine.gov.mz/ operacoes-estatisticas/censos/censo-2007/rgph-2007/indicadores-sociodemograficos-provincia-de-gaza-2007.pdf/.

22. Harris PA, Taylor R, Thielke R, Payne J, Gonzalez N, Conde JG. Research Electronic Data Capture (REDCap) - A metadata driven methodology and workflow process for providing translational research informatict support. J Biomed Inform. 2009;42(2):377-81.

23. Mohedas I, Anderson FW, Adomako J, Sienko KH. Discrepancies between clinicians and rural healthcare workers regarding referral procedures based on blood pressure measurements. Int J Gynecol Obstet. 2013;123:244-51.

24. Sengwana MJ, Puoane T. Knowledge, beliefs and attitudes of community health workers about hypertension in the Cape Peninsula. South Africa Curationis. 2004;27(1):65-71.

25. Lehmann U, Sanders D. Community health workers: What do we know about them? World Heal Organ Geneva [Internet]. 2007;(January):34 pp. Available from: http://www.who.int/hrh/documents/community_health_ workers.pdf. Accessed 20 May 2016.

26. George A, Young M, Nefdt R, Basu R, Sylla M, Clarysse G, et al. Community health workers providing government community case management for child survival in sub-Saharan Africa: who are they and what are they expected to do? Am J Trop Med Hyg. 2012;87(5 Suppl):85-91.

27. Dhakal G, Subedi M, Paudel K. Magnesium sulphate in management of severe pre-eclampsia and eclampsia. J Nepal Health Res Counc. 2012;10(21):113-7.

28. Bugalho A, Bacci A, Bergström S. Risk factors in Mozambican women with eclampsia: a case-referent study. Afr J Reprod Health. 2001;5(2):30-5.

29. Bennett S, George A, Rodriguez D, Shearer J, Diallo B, Konate M, et al. Policy challenges facing integrated community case management in Sub-Saharan Africa. Trop Med Int Health. 2014;19(7):872-82.

30. Sevene E, Lewin S, Mariano A, Woelk G, Woelk G, Oxman AD, et al. System and market failures: The unavailability of magnesium sulphate for the treatment of eclampsia and pre-eclampsia in Mozambique and Zimbabwe. Br Med J. 2005;331(7519):765-9.

31. Aaserud $M$, Lewin $S$, Innvaer S, Paulsen EJ, Dahlgren AT, Trommald M, et al. Translating research into policy and practice in developing countries: a case study of magnesium sulphate for pre-eclampsia. BMC Health Serv Res. 2005:5:68.

32. Kim YM, Ansari N, Kols A, Tappis H, Currie S, Zainullah P, et al. Prevention and management of severe pre-eclampsia/eclampsia in Afghanistan. BMC Pregnancy Childbirth. 2013;13(1):186. 
33. Bigdeli M, Zafar S, Assad H, Ghaffar A. Health System Barriers to Access and Use of Magnesium Sulfate for Women with Severe Pre-Eclampsia and Eclampsia in Pakistan: Evidence for Policy and Practice. PLoS One. 2013;8(3), e59158.

34. Harvey SA, Ayabaca P, Bucagu M, Diibrina S, Edson WN, Gbangbade S, et al. Skilled birth attendant competence: An initial assessment in four countries, and implications for the Safe Motherhood movement. Int I Gynecol Obstet. 2004;87(2):203-10.

35. Stanback J, Mbonye AK, Bekiita M. Contraceptive injections by community health workers in Uganda: A nonrandomized community trial. Bull World Health Organ. 2007:85(10):768-73.

36. Malarcher S, Meirik O, Lebetkin E, Shah I, Spieler J, Stanback J. Provision of DMPA by community health workers: What the evidence shows. Contraception. 2011;83:495-503.

37. Brunie A, Hoke TH, Razafindravony B. La distribuituion a base communautaire de contraceptifs onjectables dans le contexte africain: essai en communaute a Madagascar. Sante. 2011;21(1):21-6.

38. Socio-serve. Towards an effective collaboration for quality maternal and neonatal health delivery: The role of the traditional birth attendant and the Ghana health service. 2012

39. Schwitters A, Lederer P, Zilversmit L, Gudo PS, Ramiro I, Cumba L, et al. Barriers to health care in rural Mozambique: a rapid ethnographic assessment of planned mobile health clinics for ART. Glob Heal Sci Pract. 2015;3(1):109-16.

\section{Submit your next manuscript to BioMed Central and we will help you at every step:}

- We accept pre-submission inquiries

- Our selector tool helps you to find the most relevant journal

- We provide round the clock customer support

- Convenient online submission

- Thorough peer review

- Inclusion in PubMed and all major indexing services

- Maximum visibility for your research

Submit your manuscript at www.biomedcentral.com/submit 